\title{
Comparison of quality of anardana (dried arils) prepared in mechanical cabinet and solar tunnel drier from wild pomegranate (Punica granatum L.) fruits procured from different locations of Himachal Pradesh, India
}

\begin{abstract}
Abhimanyu Thakur*
Department of Food Science and Technology, Dr YS Parmar University of Horticulture and Forestry, Nauni, Solan-173230 (Himachal Pradesh), India

N.S. Thakur

Department of Food Science and Technology, Dr YS Parmar University of Horticulture and Forestry, Nauni, Solan-173230 (Himachal Pradesh), India

Hamid

Department of Food Science and Technology, Dr YS Parmar University of Horticulture and Forestry, Nauni, Solan-173230 (Himachal Pradesh), India

Monika Chauhan

Department of Food Science and Technology, Dr YS Parmar University of Horticulture and Forestry, Nauni, Solan-173230 (Himachal Pradesh), India

Chetna Sharma

Department of Food Science and Technology, Dr YS Parmar University of Horticulture and Forestry, Nauni, Solan-173230 (Himachal Pradesh), India

*Corresponding author. E-mail: abhimanyuthakurprashar@gmail.com

Abstract

The dried arils (anardana) prepared from wild pomegranate fruits (Punica granatum L.) are widely used as an acidulant in culinary purposes and in formulations of various ayurvedic medicines which are helpful in curing a number of ailments. As there is a wide variation among the quality of fruits which is due to geographic conditions, climatic factors and genetic variability so anardana was prepared from the fruits of different locations under different drying modes. The prepared product was further compared for its physicochemical, antioxidant and sensory characteristics. Anardana prepared under mechanical cabinet drier and solar tunnel drier was comparable in terms of its various quality characteristics. While comparing the locations for the procurement of raw material, best quality anardana in terms of various quality attributes like colour, TSS [(total soluble solids) $\left.\left(40.35^{\circ} \mathrm{B}\right)\right]$, total sugars $(26.15 \%)$, anthocyanins $(37.97 \mathrm{mg} / 100 \mathrm{~g})$, total phenols $(176.46$ mg GAE/100 g), flavonoids (39.45 mg QuE/100 g), antioxidant activity (59.53\%), starch $(2.87 \%)$ and sensory characteristics was prepared from the fruits of Karsog location (1265 meters above mean sea level) of Himachal Pradesh, India.
\end{abstract}

Keywords: Antioxidants, Arils, Cabinet drier, Drying, Locations

\section{Article Info}

https://doi.org/10.31018/

jans.vi.2247

Received: March 30, 2020

Revised: April 15, 2020

Accepted: May 1, 2020

\section{How to Cite}

Thakur, A. et al. (2020). Comparison of quality of anardana (dried arils) prepared in mechanical cabinet and solar tunnel drier from wild pomegranate (Punica granatum L.) fruits procured from different locations of Himachal Pradesh, India. Journal of Applied and Natural Science, 12(2): 71 - 78 https://doi.org/10.31018/ jans.vi.2247

\section{INTRODUCTION}

Wild pomegranate (Punica granatum L.) belongs to family Punicaceae and is one of the most important wild fruits of tropical and subtropical regions. The wild form is widely distributed in Transcaucasia and Central Asia whereas, in India, it is found in the hill slopes of Himachal Pradesh, Jammu and Kashmir and Uttarakhand at an altitude of 900 to 1800 m above mean sea level. In Himachal Pradesh, it is distributed in Solan, Sirmour, Mandi, Shimla, Kullu and Chamba districts (Ercisli et al., 2011; Thakur et al., 2011; Thakur et al., 2018). The arils of wild pomegranate are rich in various organic acids, sugars, anthocyanins, phenols, ascorbic acid, anti-oxidants and minerals (Tehranifar et al., 2010; Thakur et al., 2018). Wild pomegranate fruit is also one of the important sources of anti-oxidants which help in the prevention of neurodegenerative disorders (Kashyap et al., 2017; Thakur et al., 2018; Thakur et al., 2019). The pomegranate extracts are widely used for curing wide variety of ailments like inflammations and indigestion, vomiting, sore throat, brain diseases, spleen complaints, chest troubles, scabies, bronchitis, liver and kidney disorders (Kirtikar and Basu, 1935; Kalaycioglu and Erim, 2017). 
The wild pomegranate fruits are highly acidic in nature and due to intense sourness it is not fit for fresh consumption. So it is processed into a value added dried product known as anardana (dried arils) which is used as an acidulant in culinary purposes. Anardana is also a good source of vitamins and minerals besides improving the mouth feel of the food and digestion (Kingsly et al., 2006). This dried form of fruit is sold worth in crores of rupees at various markets throughout the country and abroad (Bakshi et al., 2013). Due to varying geographic conditions, climatic factors and genetic variability there is a wide variation in physico-chemical characteristics of wild pomegranate fruits. So present studies were carried out to prepare anardana under different drying modes viz. mechanical and solar tunnel drier and compare its various quality characteristics. Further no work has been carried out on antioxidant properties of anardana. Therefore, studies on antioxidant properties were undertaken to evaluate antioxidant potential of the anardana prepared from the wild pomegranate $(P$. granatum $L$.) fruits procured from different locations of Himachal Pradesh.

\section{MATERIALS AND METHODS}

Collection of fruit and chemicals: Wild pomegranate $(P$. granatum) fruits were procured from four locations as per the details given in Figure 1. The fruits were further used for aril extraction and the chemicals used during the entire study were procured from local market.

Preparation of dried arils (anardana): Wild pomegranate arils were extracted and pre-treated as per the method suggested by Thakur et al. (2010), where arils were steam blanched for 30 seconds followed by sulphuring with 0.30 per cent sulphur powder for 60 minutes in sulphur fumigation chamber before carrying out the drying. The pre-treated arils were spread on the perforated steel trays of dimensions $76 \times 56 \mathrm{~cm}$ in $0.50 \mathrm{~cm}$ layer and dried in mechanical cabinet and solar tunnel drier. The solar tunnel drier has been made of polyethylene sheet of thickness $0.31 \mathrm{~mm}$ and the temperature recorded in this drier during these studies was in the range of $30-45^{\circ} \mathrm{C}$. Whereas, in mechanical cabinet drier the pre treated arils were dried at a constant temperature of $60 \pm 2{ }^{\circ} \mathrm{C}$.

Quality attributes: The colour of arils was observed visually by comparing with colour charts of Royal Horticulture Society, London. Yield of dried arils was calculated on per cent basis by dividing the weight of dried arils by the weight of fresh arils. Moisture content, TSS, sugars, titratable acidity, ascorbic acid, anthocyanins, starch, NEB (non enzymatic browning), HMF (hydroxyl methyl furfural) and furfural content of dried arils was determined according to Ranganna (2009). Water activity of the dried product (anardana) was estimated by computer based digital water activity meter
$\left(\mathrm{HW}_{3}\right.$ model, Rotronic International, Switzerland). The $\mathrm{pH}$ of dried arils was determined by using a digital $\mathrm{pH}$ meter (CRISON Instrument, Ltd, Spain). Total fibres content was estimated by the method given by Gould (1978). Total phenol content was determined by Folin-Ciocalteu procedure given by Singleton and Rossi (1965) and expressed as $\mathrm{mg} / 100 \mathrm{~g}$ of GAE (Gallic Acid Equivalent). The total flavonoid content of fruit samples was estimated according to the method of llahy et al. (2011) and expressed as mg/100 $\mathrm{g}$ of QuE (Quercetin Equivalent).

Antioxidant properties: One $\mathrm{ml}$ of sample was taken which was further dissolved in $10 \mathrm{ml}$ of methanol and out of which $0.1 \mathrm{ml}$ of methanolic extract was taken for the estimation. DPPH (2,2diphenyl-1-picrylhydrazyl) was used as a source of free radical and free radical scavenging activity was measured as per the method of BrandWilliams et al. (1995) which was expressed as per cent. Metal chelating activity in terms of per cent chelation was determined according to method of Dinis et al. (1994). FRAP (ferric reducing antioxidant power) assay was estimated as per the method of Benzie and Strain (1996) and expressed as $\mu \mathrm{M} \mathrm{Fe}^{2+} / 100 \mathrm{~g}$. The method of Oktay et al. (2003) was used for the measurement of reducing power and absorbance of the extract at $700 \mathrm{~nm}$ was considered as a measurement of reducing power.

Sensory evaluation: The sensory evaluation of prepared dried aril samples was carried out by hedonic rating test as given by Amerine et al. (1965). Sensory evaluation of anardana was conducted to assess the consumer acceptance and panel of ten judges (Faculty members and students of the Department of Food Science and Technology) was selected to evaluate the product for various sensory characteristics like colour, texture, flavour and overall acceptability on a 9 point hedonic scale. Sensory evaluation was done at ambient temperature conditions and the mean score of all attributes was used to draw overall acceptability of the product. (Kumar et al., 2018).

Statistical analysis: The data on physicochemical characteristics of dried arils were analyzed by completely randomized design (CRD factorial). The data pertaining to the sensory evaluation of dried wild pomegranate arils were analyzed by randomized block design (RBD). Data on physico-chemical and sensory characteristics of dried arils during the study were replicated five times.

\section{RESULTS AND DISCUSSION}

\section{Quality attributes}

Visual colour: The data presented in Table 1 show that visual colour of anardana prepared from the fruits of different locations and drying modes was observed as Red group. The higher intensity 
Thakur, A. et al. / J. Appl. \& Nat. Sci. 12(2): 71- 78 (2020)

Table 1. Visual colour of anardana*

\begin{tabular}{lll}
\hline \multirow{2}{*}{ Location } & \multicolumn{2}{c}{ Drying mode } \\
\cline { 2 - 3 } & Cabinet drier & Solar tunnel drier \\
\hline Narag & Red 45 D & Red 45 D \\
Karsog & Red 46 B & Red 46 A \\
Basantpur & Red 45 B & Red 46 B \\
Darlaghat & Red 47 B & Red 47 A \\
\hline
\end{tabular}

${ }^{*}$ Colour card number of Royal Horticulture Society, London

of red colour observed in anardana prepared in mechanical cabinet drier might be due to faster and controlled drying conditions as compared to solar tunnel drier. These conditions might have led towards better retention of colour pigments like anthocyanins and less browning in mechanical cabinet dried arils as compared to solar tunnel dried arils. The more intense colour (Red 46 B and A) of anardana observed in Karsog location might be due to higher content of anthocyanins in the fruit as compared to other locations. Almost similar results of colour of anardana have been reported by Bhat et al. (2014) and Sharma and Thakur (2016a) in mechanical cabinet and solar tunnel dried arils.

Yield and moisture: Data appended in Fig. 2a indicate that higher yield of anardana was observed in solar tunnel drier as compared to mechanical cabinet drier and among different locations it was found highest in Narag location and lowest in Basantpur location. The higher yield of anardana observed in solar tunnel drier might be due to the retention of higher moisture content in dried product. The higher moisture content was observed in anardana dried in solar tunnel drier as compared to mechanical cabinet drier. The high- est moisture content of anardana prepared from wild pomegranate fruit of different locations was observed in Basantpur location and lowest in $\mathrm{Na}$ rag location. The lower moisture content observed in the mechanical cabinet dried arils might be due to the constant drying under controlled temperature conditions inside the mechanical cabinet drier as a result of which fast and efficient moisture removal occurred as compared to other solar tunnel drier, where fluctuating temperature conditions led to the higher moisture content. Similar trend of results of yield and moisture content of anardana has been reported by Sharma and Thakur (2016b) and Sharma et al. (2013) in anardana prepared in mechanical cabinet and solar tunnel drier.

TSS and water activity: An appraisal of data on TSS content of anardana (Fig. 2b) show that higher TSS of anardana was observed in mechanical cabinet drier as compared to solar tunnel drier. The anardana prepared from wild pomegranate fruits of different locations reveals that it was found maximum in Karsog location and minimum in $\mathrm{Na}$ rag location. The higher TSS content of anardana observed in mechanical cabinet drier might be due to lower moisture content leading to more concentration of TSS as compared to solar tunnel drier. The other reason for higher TSS in mechanical cabinet dried arils might be due to the minimum involvement of various soluble constituents in various chemical reactions as a result of faster rate of drying as compared to solar tunnel drier. The maximum TSS of anardana observed in Karsog location might be due to the maximum initial values of TSS in fruits as compared to others. The lowest water activity of anardana prepared from wild pomegranate of different locations was found in Narag

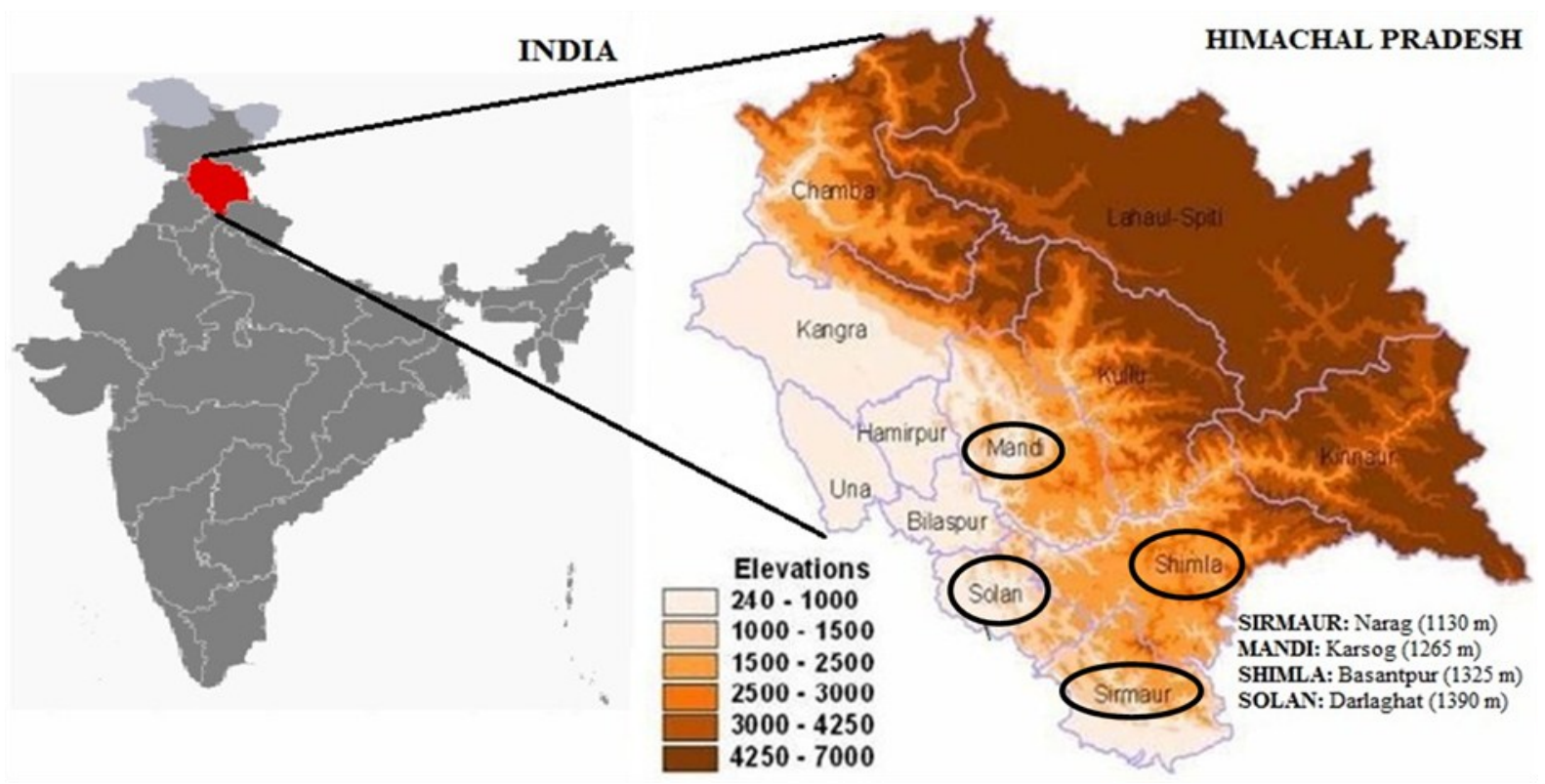

Fig. 1. Elevation map of the selected locations for procurement of wild pomegranate fruits (Image adapted from Jaswal et al., 2015). 
Thakur, A. et al. / J. Appl. \& Nat. Sci. 12(2): 71- 78 (2020)

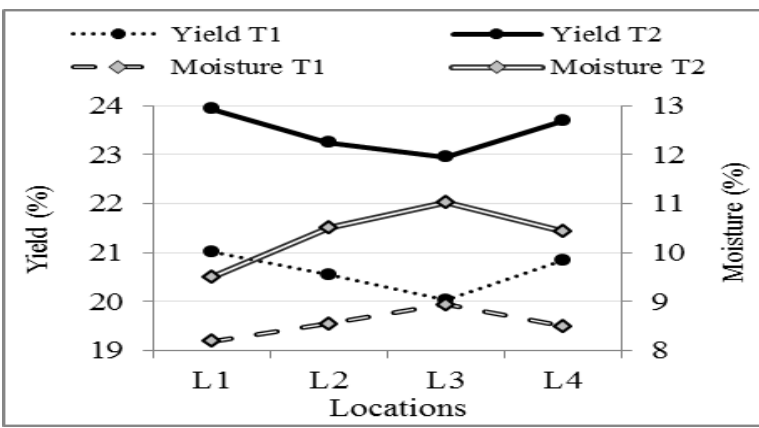

(a). Yield and moisture

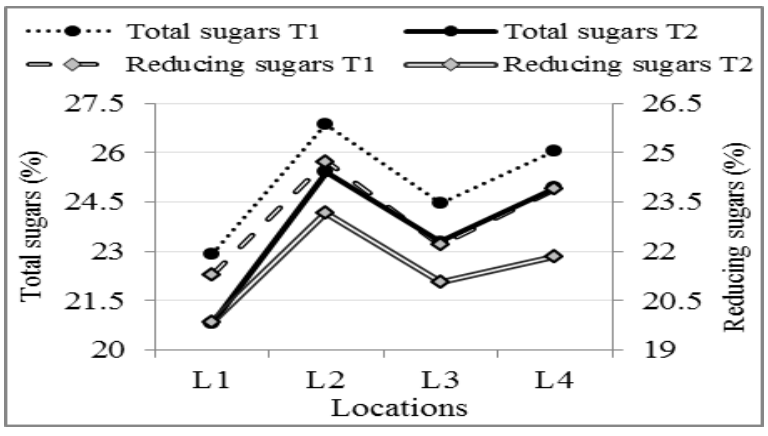

(c). Total sugars and reducing sugars

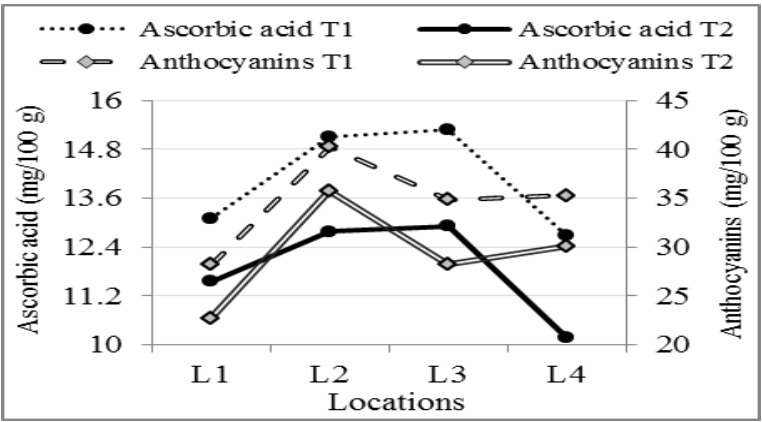

(e). Ascorbic acid and Anthocyanins

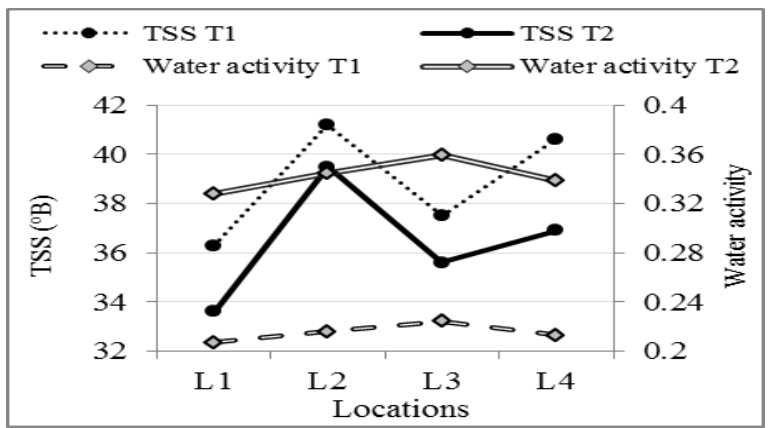

(b). TSS and water activity

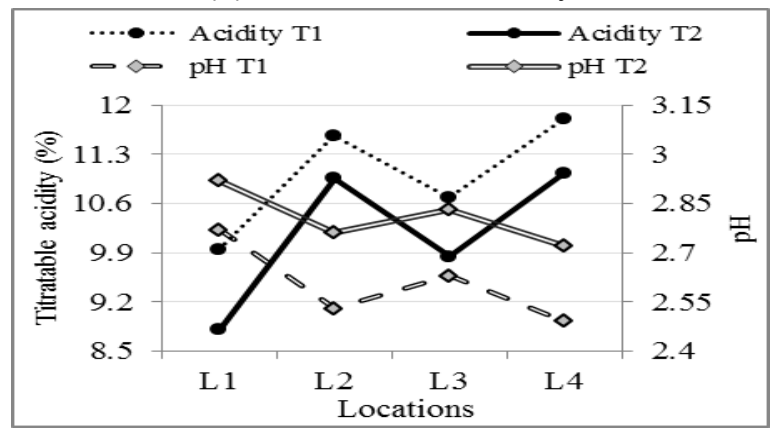

(d). Titratable acidity and $\mathrm{pH}$

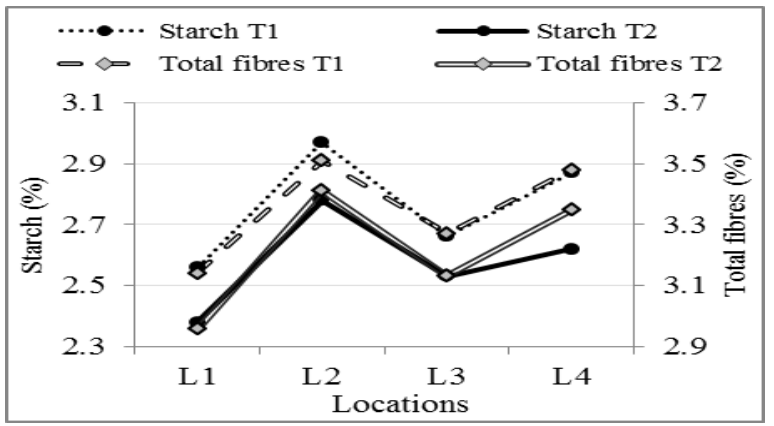

(f). Starch and total fibres

Fig. 2(a-f). Physico-chemical characteristics of anardana prepared from the fruits of different locations under various drying modes ( $T_{1}$ : Mechanical cabinet $T_{2}$ and Solar tunnel drier; $L_{1}:$ Narag, $L_{2}:$ Karsog, $L_{3}$ : Basantpur and $L_{4}$ : Darlaghat).

location and highest in Basantpur location. Among both drying modes, the lower water activity was recorded in mechanical cabinet drier which might be due to constant drying under controlled temperature conditions inside the mechanical cabinet drier as a result of which fast and efficient moisture removal occurred as compared to solar tunnel drier. Similar trend of results of TSS of anardana has been reported by Bhat et al. (2014) and More et al. (2017) in mechanical cabinet and solar tunnel dried arils.

Total sugars and reducing sugars: Perusal of the data given in Fig. $2 \mathrm{c}$ reveal that higher total and reducing sugars content was observed in mechanical cabinet drier as compared to solar tunnel drier. The overall effect of locations shows that the sugars content was found maximum in Karsog location and minimum in Narag location. The higher total and reducing sugars content of anardana in mechanical cabinet drier might be due to the lower initial moisture content leading to more concentration of the sugars in the end product. The other possible reason for this might be due to reduced rate of involvement of reducing sugars in various chemical reactions including browning because of the faster drying and lower moisture content in mechanical cabinet drier. Similar trend of results of total and reducing sugars of anardana has been reported by Sharma et al. (2013), Bhat et al. (2014), Sharma and Thakur (2016a) and Sharma and Thakur (2016b) in mechanical cabinet and solar tunnel dried arils.

Titratable acidity and pH: The overall effect of drying modes given in Fig. $2 d$ shows that higher acid and lower $\mathrm{pH}$ of anardana was observed in mechanical cabinet drier as compared to solar tunnel drier. The highest acid and lowest $\mathrm{pH}$ of anardana prepared from wild pomegranate fruits 
Thakur, A. et al. / J. Appl. \& Nat. Sci. 12(2): 71 - 78 (2020)

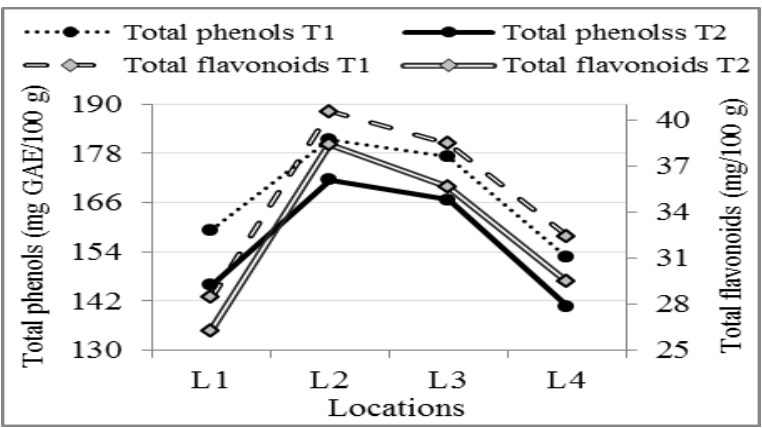

(g). Total phenols and total flavonoids

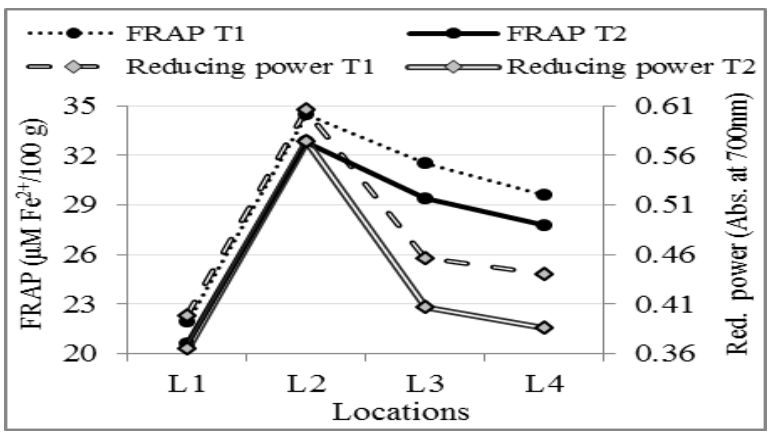

(i). FRAP and reducing power

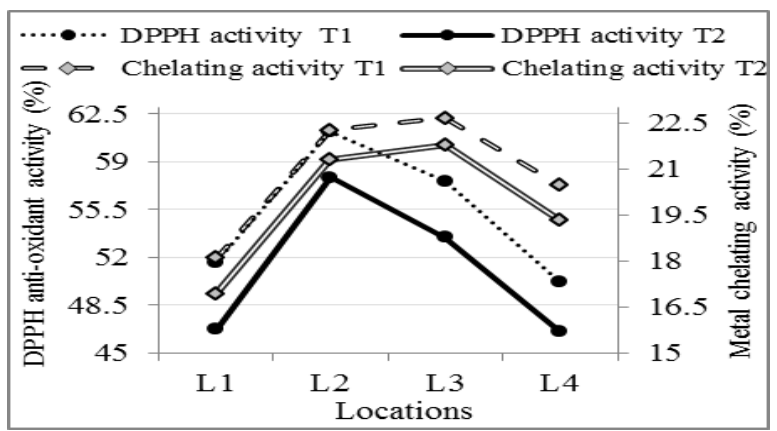

(h). DPPH activity and metal chelating activity

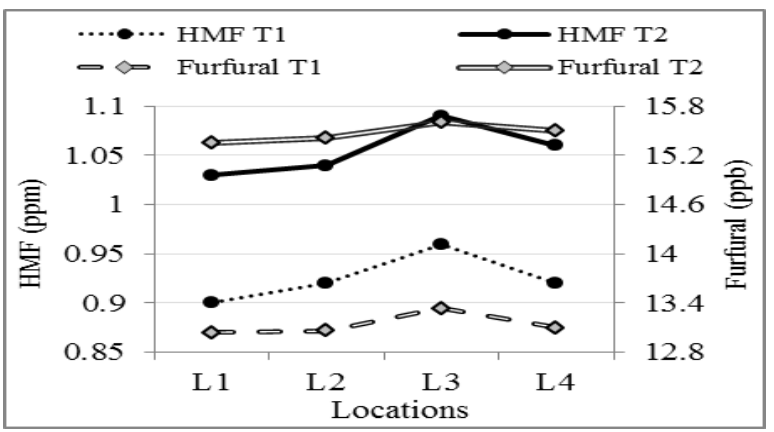

(j). HMF and furfural

Fig. 2(g-j). Physico-chemical characteristics of anardana prepared from the fruits of different locations under various drying modes ( $T_{1}$ : Mechanical cabinet and $T_{2}$ : Solar tunnel drier; $L_{1}:$ Narag, $L_{2}:$ Karsog, $L_{3}$ : Basantpur and $L_{4}$ : Darlaghat).

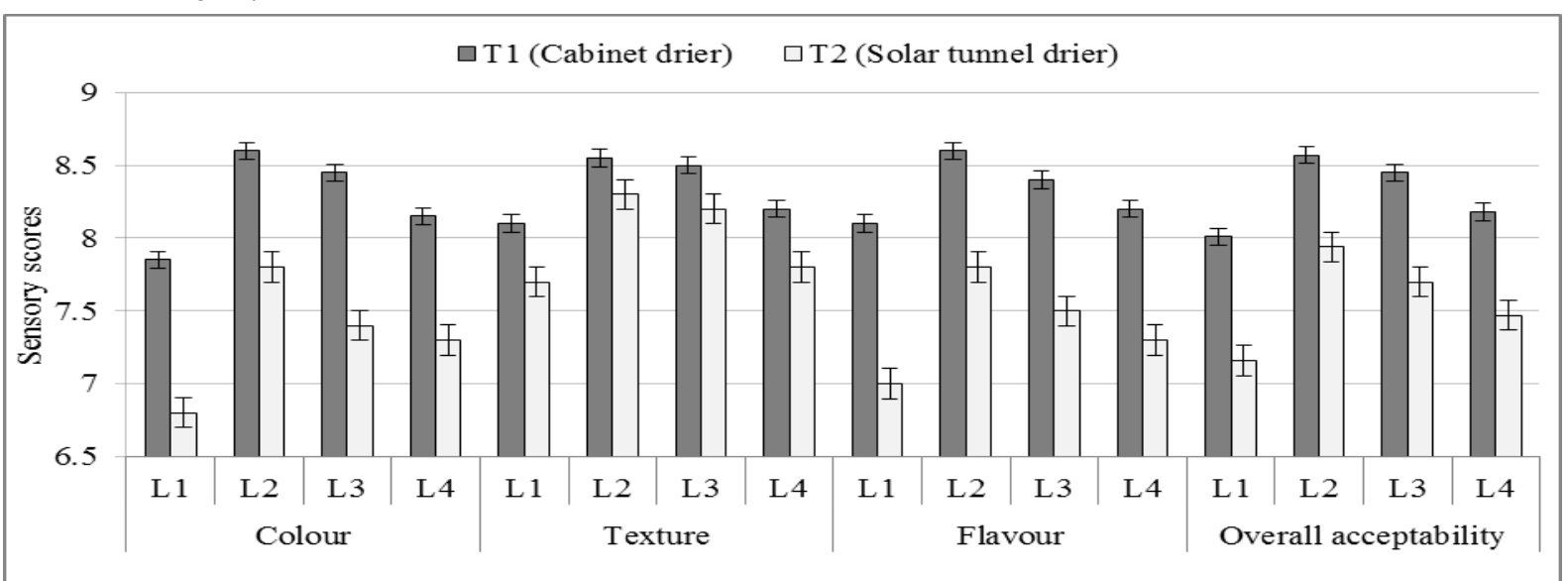

Fig. 3. Sensory characteristics scores of anardana prepared from the fruits of different locations under various drying modes $\left(T_{1}\right.$ : Mechanical cabinet and $T_{2}$ : Solar tunnel drier; $L_{1}:$ Narag, $L_{2}:$ Karsog, $L_{3}$ : Basantpur and $L_{4}$ : Darlaghat) (error bars indicates standard deviations of the average).

was found maximum in Darlaghat location whereas, the lowest acid and highest $\mathrm{pH}$ was observed in Narag location. The higher acid and lower $\mathrm{pH}$ was recorded in mechanical cabinet drier which might be due to lower initial moisture content leading to higher concentration of acids in anardana. The other possible reason for this might be due to reduced rate of involvement of acids in various browning reactions because of the faster drying and lower moisture content in mechanical cabinet drier. The highest acid and lowest $\mathrm{pH}$ of anardana observed in Darlaghat location might be due to high acid content in fruits as compared to others.
The results obtained for acid content and $\mathrm{pH}$ of anardana are near to those reported earlier by Kingsley et al. (2006) and Sharma and Thakur (2016b) in mechanical cabinet and solar tunnel drier.

Ascorbic acid and anthocyanins: An appraisal of data given in Fig. $2 \mathrm{e}$ reveal that higher ascorbic acid and anthocyanins content of anardana was observed in mechanical cabinet drier and lower in solar tunnel drier. The ascorbic acid content of anardana was found maximum and minimum in Basantpur and Darlaghat location, respectively. The anthocyanins content of anardana was ob- 
served maximum in Karsog location and minimum in Narag location. The maximum retention of ascorbic acid and anthocyanins content in cabinet dried arils might be due to the controlled drying conditions in mechanical cabinet drier and non exposure of arils to intermittent drying cycles and fluctuating temperatures as experienced by the arils in solar tunnel drier. The other reason for the same might be due to lower moisture content leading to more concentration of ascorbic acid and anthocyanins in the end product. The highest ascorbic acid and anthocyanins content of anardana observed in Basantpur and Karsog locations might be due to higher initial values in fruits as compared to others. Above results for ascorbic acid and anthocyanins content are comparable to the findings of Kingsley et al. (2006), Bhat et al. (2014) and Sharma and Thakur (2016b) in anardana prepared in mechanical cabinet and solar tunnel drier.

Starch and total fibres: Perusal of the data on starch content (Fig. 2f) of anardana reveal that the higher starch content of anardana was observed in mechanical cabinet drier as compared to solar tunnel drier. Among different locations it was found maximum in Karsog location and minimum in Narag location. The higher total fibres content of anardana was observed in mechanical cabinet drier as compared to solar tunnel drier. The total fibres content of anardana was found maximum in Karsog location and minimum in Narag location. The higher content of starch and total fibres in anardana recorded in mechanical cabinet drier might be due to lower moisture content leading to more concentration of starch and total fibres in end product. The maximum starch and total fibres content of anardana recorded in Karsog location might be due to the maximum initial values in fruits as compared to others. Nearly similar trend of results for starch content of anardana have been reported by Sharma and Thakur (2016b).

Total phenols and total flavonoids: An appraisal of data given in Fig. $2 g$ reveals that higher total phenol and flavonoid content of anardana was observed in mechanical cabinet drier as compared to solar tunnel drier. The arils dried in mechanical cabinet drier had more phenols which might be due to the involvement of phenols in enzymatic reactions to a lesser extent because of fast drying as compared to solar tunnel drying. The maximum retention of total flavonoids in mechanical cabinet dried arils might be due to controlled drying conditions in mechanical cabinet drier and no exposure of arils to intermittent drying cycles and fluctuating temperatures as experienced by the arils in solar tunnel drier. Among different locations the total phenol content was found maximum in Karsog location and minimum in Darlaghat location. The total flavonoids content of anardana was found maximum in Karsog loca- tion and minimum in Narag location. The highest total phenol and flavonoid content of anardana observed in Karsog location might be due to the higher initial content in the fruits of respective location. Similar trend of results of total phenols of anardana has been reported by Bhat et al. (2014), Sharma and Thakur (2016a) and Sharma and Thakur (2016b) in mechanical cabinet and solar tunnel dried arils.

Antioxidant properties: Data pertaining to various antioxidant properties of anardana prepared from wild pomegranate fruits of different locations under various drying modes (mechanical cabinet and solar tunnel drier) is presented in Fig. $2 \mathrm{~h}$ and $2 \mathrm{i}$. The higher antioxidant values were observed in arils dried in mechanical cabinet drier as compared to solar tunnel drier. The maximum values for various antioxidant properties of anardana in cabinet drier might be due to the better stability of various antioxidant compounds during faster and continuous drying as compared to solar tunnel drier. The fast drying rate reduced the exposure time of arils for various chemical and oxidation processes leading to higher antioxidant properties in mechanical cabinet dried arils. Among different locations the highest DPPH antioxidant activity, FRAP and reducing power was found maximum in Karsog location Metal chelating activity of anardana prepared from wild pomegranate fruits was found highest in Basantpur location followed by Karsog location. The maximum values for the antioxidant properties of anardana observed in Karsog location might be due to the higher initial values of various antioxidants compounds like ascorbic acid, total phenols, anthocyanins and total flavonoids in the fruits of this location as compared to others.

NEB, HMF and furfural: The NEB (in terms of optical density) of wild pomegranate arils dried in mechanical cabinet drier was observed as 0.040 $\left(L_{1}\right), 0.042\left(L_{2}\right), 0.045\left(L_{3}\right)$ and $0.041\left(L_{4}\right)$ whereas, a higher values of NEB as $0.085\left(L_{1}\right), 0.090\left(L_{2}\right)$, $0.095\left(L_{3}\right)$ and $0.091\left(L_{4}\right)$ were observed in solar tunnel dried samples. The lower NEB of anardana observed in mechanical cabinet drier might be due to fast drying rate and uniform drying which minimized the chances of oxidative and nonenzymatic degradation along with the formation of polymerization products which are ultimately responsible for browning. Data presented in Fig. $2 \mathrm{j}$ reveal that lower HMF and furfural of anardana was observed in mechanical cabinet drier as compared to solar tunnel drier. Among different locations the HMF and furfural content was recorded minimum in Narag location and maximum in Basantpur location. Arils dried in the mechanical cabinet drier recorded the lowest values for HMF which might be due to slower degradation of hexose sugars to form HMF because of efficient moisture removal and fast drying of arils under con- 
trolled conditions of temperature. The anardana prepared in mechanical cabinet drier recorded the lowest values for furfural which might be attributed to the inhibition of polymerization of ascorbic acid to form furfural because of lowering the moisture of arils through efficient moisture removal and fast drying of arils under controlled conditions of temperature. The above results for NEB, HMF and furfural content of anardana were in conformity with the finding of Singh and Kingsley (2008), Singh and Dayal (2011), Bhat et al. (2014) and Sharma and Thakur (2016a) in mechanical cabinet and solar tunnel dried arils.

Sensory characteristics: Data presented in Fig. 3 reveal that highest sensory scores for colour, texture, flavour and overall acceptability were obtained in anardana dried in cabinet drier as compared to solar tunnel drier. Among different locations these scores were obtained highest in Karsog location and lowest in Narag location. The higher colour score observed in cabinet dried arils might be due to faster drying rate which minimized the browning of dried arils as a result of which judges awarded higher scores of colour as compared to solar tunnel dried arils. The highest colour score of anardana obtained in Karsog location might be due to high initial colour pigment in the fruit as compared to others. The higher texture score of anardana in mechanical cabinet drier might be due to the low moisture content in the arils which might have provided better texture to the end product and consequently judges awarded the higher texture scores. The higher flavour score in mechanical cabinet dried arils might be due to better retention of sugars, acid and other chemical constituents in the product which led the judges to award the higher flavour scores. The highest flavour score of anardana obtained in Karsog location might be due to better blend of acid and sugars observed by the judges in the product as compared to others. The reason of best score of overall acceptability in mechanical cabinet dried arils might be due to better combination of colour, texture and flavor constituents of anardana in this drier, thereby improving the overall acceptability score. The drying under controlled temperature conditions in mechanical cabinet drier reduced the drying time and therefore lowered the moisture content of cabinet dried arils and helped in preventing deteriorative chemical reactions like Maillard and other associative reactions due to which maximum overall acceptability score was awarded by the judges. The better combination of colour, texture and flavour of anardana in Karsog location might have led towards higher overall acceptability score in this location. Nearly similar trend of results for the sensory characteristics of anardana have been reported by Thakur et al. (2010), Bakshi et al. (2013), Bhat et al. (2014), Sharma and Thakur (2016a), Sharma and Thakur (2016b) and More et al. (2017) in mechanical cabinet and solar tunnel drier.

\section{Conclusion}

The anardana prepared from wild pomegranate fruits (Punica granatum) in mechanical cabinet drier was rated better in terms of various quality attributes as compared to solar tunnel drier. The quality attributes like colour, TSS, sugars, anthocyanins, total phenols, flavonoids and antioxidant activity were observed higher in anardana in Karsog location. In this location the sensory scores of anardana were also obtained highest among all the locations. Thus, it was concluded that anardana prepared from the fruits of Karsog location under mechanical cabinet drier was found to be better on the basis of various quality attributes (TSS, sugars, anthocyanins, total phenols, flavonoids and antioxidant activity) and sensory characteristics (colour, texture flavour and overall acceptability) as compared to other locations.

\section{REFERENCES}

1. Amerine, M.A., Pangborn, R.M. and Roessler, E.B. (1965). Principles of Sensory Evaluation of Food. Academic Press, London.

2. Bakshi, P., Bhushan, B., Wali, V.K., Bakshi, M., Sharma, A. and Bhat, D.J. (2013). Standardization of drying method and organoleptic evaluation of wild pomegranate (anardana) seeds. World Journal of Agricultural Sciences, 9(5), 397-400. https:// www.doi.org/10.5829/idosi.wjas.2013.9.5.1750

3. Benzie, I.F. and Strain, J.J. (1996). The ferric reducing ability of plasma (FRAP) as a measure of antioxidant power: the FRAP assay. Analytical Biochemistry, 239(1), 70-76. https://www.doi.org/10.1006/ abio.1996.0292

4. Bhat, M.M., Thakur, N.S. and Jindal, N. (2014). Studies on the effect of drying methods and packaging on quality and shelf life of dried wild pomegranate arils. Asian Journal of Dairy and Food Research, 33, 1824. 0563.33.1.005

5. Brand-Williams, W., Cuvelier, M.E. and Berset, C. (1995). Use of free radical method to evaluate antioxidant activity. Lebensmittel-Wissenschaft and Technology, 28, 25-30.

6. Dinis, T.C., Madeira, V.M. and Almeida, L.M. (1994). Action of phenolic derivatives (acetaminophen, salicylate, and 5-aminosalicylate) as inhibitors of membrane lipid peroxidation and as peroxyl radical scavengers. Archives in Biochemistry and Biophysics, 315 (1), 161-169. https://www.doi.org/10.1006/ abbi.1994.1485

7. Ercisli, S., Gadze, J., Agar, G., Yildirim, N. and Hizarci, Y. (2011). Genetic relationships among wild pomegranate (Punica granatum) genotypes from coruh valley in Turkey. Genetics and Molecular Research, 10, 459-464. https://www.doi.org/10.4238/vol10$1 \mathrm{gmr} 1155$

8. Gould, W.A. (1978). Food Quality Assurance. AVI Publishing Company, Westport, Connecticut, New York.

9. Ilahy, R., Hdider, C., Lenucci, M.S., Tlili, I. and Dales- 
sandro, G. (2011). Antioxidant activity and bioactive compound changes during fruit ripening of highlycopene tomato cultivars. Journal of Food Composition and Analysis, 24(4-5), 588-595. https:// www.doi.org/10.1016/j.jfca.2010.11.003

10.Jaswal, A.K., Bhan, S.C., Karandikar, A.S. and Gujar, M.K. (2015). Seasonal and annual rainfall trends in Himachal Pradesh during 1951-2005. Mausam, 66 (2), 247-264.

11.Kalaycioglu, Z. and Erim, F.B. (2017). Total phenolic contents, antioxidant activities, and bioactive ingredients of juices from pomegranate cultivars worldwide. Food Chemistry, 221, 496-507. https:// www.doi.org/10.1016/j.foodchem.2016.10.084

12.Kashyap, P., Anand, S. and Thakur, A. (2017). Evaluation of antioxidant and antimicrobial activity of Rhododendron arboreum flowers extract. International Journal of Food and Fermentation Technology, 7 (1), 123-128. https://www.doi.org/10.5958/22779396.2017.00013.7

13.Kingsly, A.R.P., Singh, D.B., Manikantan, M.R. and Jain, R.K. (2006). Moisture dependent physical properties of dried pomegranate seeds (anardana). Journal of Food Engineering, 75, 492-496. https:// www.doi.org/10.1016/j.jfoodeng.2005.04.033

14.Kirtikar, K.R. and Basu, B.D. (1935). Indian Medicinal Plants. Lalit Mohan Basu, Dehradun.

15.Kumar, V., Kushwaha, R., Goyal, A., Tanwar, B. and Kaur, J. (2018). Process optimization for the preparation of antioxidant rich ginger candy using beetroot pomace extract. Food Chemistry, 245, 168-177. https://www.doi.org/10.1016/j.foodchem.2017.10.089

16.More, V.R., Kapse, B.M., Kadam, A.R. and Pimpalpalle, L.V. (2017). Studies on drying of pomegranate arils for preparation of anardana. International Journal of Chemical Studies, 5(3), 724-728.

17.Oktay, M., Gulein, I. and Kufrevioglu, O.I. (2003). Determination of in vitro antioxidant activity of fennel (Foeniculum vulgare) seed extracts. LWT-Food Science and Technology, 36, 263-271. https:// doi.org/10.1016/S0023-6438(02)00226-8

18.Ranganna, S. (2009). Handbook of Analysis and Quality Control for Fruit and Vegetable Products. Tata McGraw Hill, pub. Co. Ltd., New Delhi.

19.Sharma, S.R., Bhatia, S., Arora, S., Mittal, T.C. and Gupta, S.K. (2013). Effect of storage conditions and packaging material on quality of anardana. International Journal of Advanced Engineering Technology, 6(5), 2179-2186.
20.Sharma, A. and Thakur, N.S. (2016a). Influence of active packaging on quality attributes of dried wild pomegranate (Punica granatum L.) arils during storage. Journal of Applied and Natural Science, 8(1), 398-404. https://doi.org/10.31018/jans.v8i1.806

21.Sharma, A. and Thakur, N.S. (2016b). Comparative studies on quality attributes of open sun and solar poly-tunnel dried wild pomegranate arils. International Journal of Bio-Resource and Stress Management, 7 (1), 136-141. https://www.doi.org/10.5958/09764038.2016.00022.1

22.Singh, D. and Dayal, H. (2011). Drying of pomegranate seeds (anardana) under different conditions. Acta Horticulturae, 890, 433-439. https:// www.doi.org/10.17660/ActaHortic.2011.890.59

23.Singh, D.B. and Kingsly, A.R.P. (2008). Effect of convective drying on quality of anardana. Indian Journal of Horticulture, 65(4), 413-416.

24.Singleton, V.L. and Rossi, J.A. (1965). Colorimetry of total phenolics with phosphomolybedic phosphotungstic acid reagent. American Journal of Enology and Viticulture, 16, 144-158.

25.Tehranifar, A., Zarei, M., Nemati, Z., Esfandiyari, B. and Vazifeshenas, M.R. (2010). Investigation of physico-chemical properties and antioxidant activity of twenty Iranian pomegranate (Punica granatum L.) cultivars. Scientia Horticulturae, 126, 180-185. https:// www.doi.org/10.1016/j.scienta.2010.07.001

26.Thakur, A., Joshi, V.K. and Thakur, N.S. (2019). Immunology and its relation with food components: an overview. International Journal of Food and Fermentation Technology, 9(1), 1-16. https:// www.doi.org/10.30954/2277-9396.01.2019.3

27.Thakur, A., Thakur, N.S., Hamid and Kumar, P. (2018). Studies on physico-chemical and antioxidant properties of wild pomegranate fruits in different locations of Himachal Pradesh, India. International Journal of Current Microbiology and Applied Sciences, 7 (8), 2842-2850. https://www.doi.org/10.20546/ ijcmas.2018.708.299

28.Thakur, N.S., Bhat, M.M., Rana, N. and Joshi, V.K. (2010). Standardization of pre-treatments for the preparation of dried arils from wild pomegranate. Journal of Food Science and Technology, 47(6), 620625. https://www.doi.org/10.1007/s13197-010-0091-4

29.Thakur, N.S., Dhaygude, G.S. and Gupta, A. (2011). Physico-chemical characteristics of wild pomegranate fruits in different location of Himachal Pradesh. International Journal of Farm Science, 1(2), 37-44. 